\title{
Aplikasi Usia Kehamilan dan Berat Janin Berbasis Android
}

\author{
Ranas Putra Tanjung ${ }^{1}$, Ade Mubarok ${ }^{2}$ \\ 1,2Teknik Informatika, Universitas ARS \\ e-mail: ${ }^{1}$ ranas.putra@gmail.com, ${ }^{2} \underline{\text { adem @ ars.ac.id }}$

\begin{tabular}{ccc}
\hline Diterima & Direvisi & Disetujui \\
$11-02-2021$ & $10-03-2021$ & $31-03-2021$ \\
\hline
\end{tabular}

\begin{abstract}
Abstrak - Menentukan awal mula kehamilan serta usia kehamilan merupakan hal penting untuk dapat mengetahui perkembangan kehamilannya. Usia kehamilan dapat diketahui salah satunya dengan mengetahui hari pertama haid terakhir (HPHT). Tujuan penelitian ini adalah membuat sebuah aplikasi yang lebih praktis untuk digunakan bagi para ibu yang sedang hamil agar mendapatkan pengetahuan tentang perkembangan usia kehamilannya, prediksi jadwal persalinan serta informasi seputar kehamilan lainnya. Metode perancangan sistem yang digunakan pada penelitian ini adalah System Development Life Cycle (SDLC) dengan menggunakan model proses waterfall. Waterfall atau sering juga disebut air terjun adalah sebuah metode dalam pengembangan sistem yang dilakukan untuk membuat pembaruan sistem yang berjalan. pengembangan sistem merupakan proses mengembangkan atau mengubah suatu sistem perangkat lunak dengan menggunakan metodemetode atau model-model yang digunakan orang untuk mengembangkan sistem-sistem perangkat lunak sebelumnya dengan memiliki alur hidup perangkat lunak secara sekuensial atau terurut dimulai dari analisis, desain, pengodean, pengujian, dan tahap pendukung. Berdasarkan implementasi dan hasil pengujian aplikasi yang telah penulis buat dapat ditarik kesimpulan berhasil dilakukan dan diimplementasikan ke target pengguna yaitu ibu hamil yang menggunakan smartphone berbasis Android.
\end{abstract}

Kata Kunci: Hari Pertama Haid terakhir (HTHP), Waterfall, Kehamilan

\begin{abstract}
Determining the onset of pregnancy and gestational age is important in order to know the progress of her pregnancy. One of the ways to determine gestational age is by knowing the first day of the last menstrual period (HPHT). The aim of this study is to make an application that is more practical to use for mothers who are pregnant to gain knowledge about the development of their gestational age, prediction of delivery schedules and information about other pregnancies. . The system design method used in this study is the System Development Life Cycle (SDLC) using the waterfall process model. Waterfall or often called a waterfall is a method in system development that is done to make system updates running. system development is the process of developing or changing a software system using methods or models used by people to develop previous software systems by having a software life flow sequentially or sequentially starting from analysis, design, coding, testing, and support stage. Based on the implementation and test results of the application that the author has made, it can be concluded that it has been successfully carried out and implemented to target users, namely pregnant women who use Android-based smartphones.
\end{abstract}

Keywords: First Day of Last Menstruation (HTHP), Waterfall, Pregnancy

\section{Pendahuluan}

Perkembangan teknologi informasi dan komunikasi pada saat ini semakin cepat dan pesat, hampir seluruh aspek kehidupan berhubungan dengan teknologi informasi dan komunikasi. Teknologi informasi dan komunikasi tidak lagi menjadi sesuatu yang baru ditengah masyarakat karena masyarakat telah banyak memanfaatkan teknologi informasi dalam menjalani aktivitas sehari-harinya. Terlebih setelah adanya penemuan perangkat mobile seperti handphone, yang saat ini siapapun dan kalangan manapun bisa memilikinya.

Handphone sangat berpengaruh pada kehidupan masyarakat pada zaman ini. Pada saat ini handphone bukan saja berfungsi sebagai alat 
komunikasi, tetapi juga sebagai alat media sosial dan pencari informasi yang bisa dilakukan melalui fasilitas internet yang ada pada handphone. Untuk menjalankan fungsi-fungsi yang terdapat pada handphone diperlukan sebuah Operating System (OS). Salah satu system operasi yang banyak digunakan saat ini adalah sistem operasi android (Venny et al., 2019:232).

Didalam system operasi android terdapat banyak aplikasi yang dapat membatu meringankan pekerjaan manusia salah satunya adalah Aplikasi mobile yang dapat membantu wanita hamil terutama yang memiliki tingkat aktivitas yang tinggi, ini banyak digunakan karena dukungan aplikasinya yang luas yang bisa di download oleh penggunanya melalui Android Market atau Playstore.

Melalui sebuah aplikasi, masyarakat khusus nya ibu hamil, dapat mengetahui dan mempelajari tentang kehamilan itu sendiri karena kehamilan merupakan hal yang sangat penting bagi semua calon ibu, dimana semua calon ibu pasti akan memberikan perhatian dan perawatan terbaik terhadap kandungannya. Sembilan bulan menjalani masa kehamilan bukanlah hal yang mudah. Banyak ibu hamil terutama ibu-ibu muda dengan kehamilan pertama khawatir dalam menghadapi dan menjalani kehamilan.

Menurut Data SDKI dalam (Carudin \& Apriningrum, 2018:116) menyebutkan bahwa "AKI dan AKB Indonesia masih cukup tinggi, angka kematian ibu (AKI) sebanyak 359/100.000 kelahiran hidup dan angka kematian bayi (AKB) sebanyak 32/1000 kelahiran hidup. Masih tingginya AKI dan AKB disebabkan karena faktor penyebab langsung, diantaranya komplikasi kehamilan, persalinan dan nifas". Kurangnya pengetahuan tentang kehamilan serta kurangnya perhatian baik dari diri sendiri (ibu hamil) maupun suami atas kebutuhan saat kehamilan merupakan hambatan bagi seorang calon ibu dalam menjalani masa kehamilan.

Menentukan awal mula kehamilan serta usia kehamilan merupakan hal penting untuk dapat mengetahui perkembangan kehamilannya. Usia kehamilan dapat diketahui salah satunya dengan mengetahui hari pertama haid terakhir (HPHT) seorang perempuan, namun kenyataan di lapangan banyak perempuan yang tidak memperhatikan siklus menstruasinya, hal ini akan dapat mempersulit tenaga kesehatan dalam menentukan usia kehamilan secara manual, meskipun saat ini sudah ada alat USG yang dapat mengidentifikasi usia kehamilan, namun demikian informasi HPHT dari seorang ibu dapat memberikan data yang cukup akurat dalam mengidentifikasi kehamilan. Felicia et al., dalam (Fajar \& Suharyanto, 2019:232).

Menurut (Tawakal et al., 2015:31) "Untuk menghitung biometri janin dan memprediksi usia sertaberat janin dapat dilakukan dengan menggunakan beberapa pendekatan. Pendekatan yang dilakukan antara lain dengan menghitung biparetal diameter (BPD), occipito-frontal diameter (OFD), head circumference (HC) dan femur length (FL)". Penelitian mengenai bagaimana menghitung biometri janin secara otomatis melalui citra USG juga telah dilakukan beberapa tahun belakangan ini.

Proses pemantauan yang selama ini ada adalah dengan aktif melakukan pengontrolan dan kunjungan ke tenaga medis seperti bidan dan dokter kandungan. Untuk daerah dengan jumlah tenaga medis yang terbatas, konsultasi dan kunjungan kepada petugas medis menjadi lebih sulit. Karenanya diperlukan sebuah sistem yang menanggulangi keterbataasan jarak tersebut, sehingga proses pemantauan tetap dapat dilakukan meskipun terpisah secara fisik.

Melihat permasalahan hal yang di atas, penulis mendapatkan ide serta motivasi untuk membuat sebuah sebuah aplikasi yang berjudul "Aplikasi Usia kehamilan dan Berat Janin Berbasis Android", yang diharapkan dengan aplikasi ini dapat berguna sebagai panduan serta informasi seputar masa kehamilannya yang disajikan secara menarik dan praktis untuk digunakan.Tinjauan pustaka dapat digunakan oleh penulis dalam bab "Pendahuluan" untuk menjelaskan perbedaan penelitian dengan artikel lainnya, bahwa tulisan merupakan inovasi terbaru. Jika penelitian memiliki orisinalitas tinggi, yang mengusulkan metode atau algoritma baru, bab tambahan setelah "Pendahuluan" dan sebelum "Metode Penelitian" dapat ditambahkan untuk menjelaskan secara singkat metode atau algoritma yang diusulkan.

\section{Metode Penelitian}

Metode penelitian ini dilakukan dengan beberapa tahapan sebagai berikut:

1. Pengumpulan data

Penelitian ini memerlukan data yang diambil oleh penulis merupakan data dari studi literature yaitu dengan cara membaca bukubuku dan jurnal sesuai dengan data yang di butuhkan. Pada penelitian ini penulis memilih studi literature yang berhubungan dengan aplikasi usia kehamilan dan berat jain menggunakan metode hari pertama haid terakhir (HPHT) 
2. Desain Aplikasi

Desain aplikasi yang dibangung oleh penulis menggunakan android studio dan menggunakan bahasa pemrograman java. Kebutuhan yang sudah dianalisa dalam bentuk desain interface dan desain struktur data menggunakan UML.

3. Testing

Dalam tahap ini penulis melakukan pengujian aplikasi sistem menggunakan black box testing untuk menguji apakah aplikasi berjalan dengan benar dan sesuai.

\subsection{Metode Algoritma}

\section{A. Android}

Menurut (Lengkong et al., 2015:20) Android adalah sistem operasi bergerak (mobile operating system) yang mengadopsi system operasi linux, namun telah dimodifikasi. Android diambil alih oleh Google pada tahun 2005 dari Android,Inc sebagai bagian strategi untuk mengisi pasar sistem operasi bergerak. Google mengambil alih seluruh hasil kerja Android termasuk tim yang mengembangkan Android.

\section{B. Metode Pengembangan Aplikasi}

Metode pengembangan aplikasi yang digunakan dalam pembuatan aplikasi usia kehamilan dan berat janin dengan model SDLC (System Development Life Cycle) dalam bentuk waterfall (air terjun). Terdapat beberapa tahapan diantaranya adalah requirement definition, softweare design, implementation and unit testing, verification and system testing dan operation and maintenance.

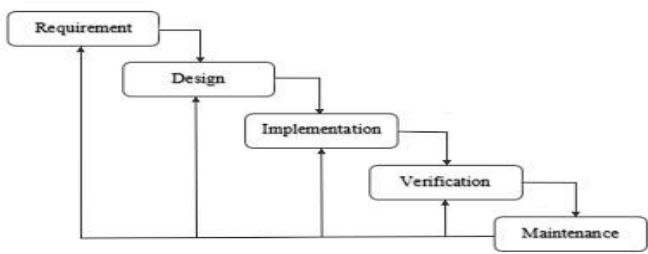

Gambar II.1 Model SDLC

\section{Requirement Definition}

Dalam tahapan ini penulis melihat dari penelitian sebelumnya untuk mendapatkan atau mengumpulkan data-data mengenai usia kehamilan dan berat janin untuk melengkapi data aplikasi ini.

\section{Software Design}

Dalam tahap ini penulis membagi kebutuhan hardware dan software yang akan digunakan dalam pembuatan aplikasi usia kehamilan dan berat janin. Penulis membuat perancangan dengan UML, use case diagram, activity diagram dan sequence diagram.

3. Implementation and Unit Testing

Dalam tahap ini penulis melakukan testing menggunakan blackbox yang menguji terhadap detail perancangan aplikasi usia kehamilan dan berat janin.

4. Verification

Dalam tahap ini penulis akan mengintegrasikan sistem ke bentuk print out berupa laporan untuk di verifikasi.

5. Operation and Maintenance

Penulis akan melakukan pemeliharaan perangkat komputer yang digunakan agar tetap berjalan dengan baik.

\section{Hasil dan Pembahasan}

Pada tahap ini difokuskan pada desain software architecture dan user interface dalam pembuatan aplikasi usia kehamilan dan berat janin berbasis android.

\subsection{Analisis Sistem dan Perancangan Diagram}

Dalam tahap ini penulis menggunakan model UML dalam perancangan diagram. Berikut UML aplikasi usia kehamilan dan berat janin

\section{A. Activity Diagram}

Activity diagram adalah diagram yang menggambarkan alir kegiatan atau aktivitas yang ada dalam sistem.

1. Activity Diagram Usia Kehamilan Activity Diagram belanja merupakan aktifitas yang dilakukan oleh user atau pengguna untuk mengetahui menu usisa kehamilan. Dalam Activity Diagram ini terdapat beberapa aktifitas, yaitu:

a) Pengguna memilih usia kehamilan pada menu

b) Sistem menampilkan pilihan

c) Pengguna mengisi form tanggal HPHT, tanggal konsepsi, dan tanggal sekarang

d) Sistem nampilkan hasil pada form tanggal perkiraan

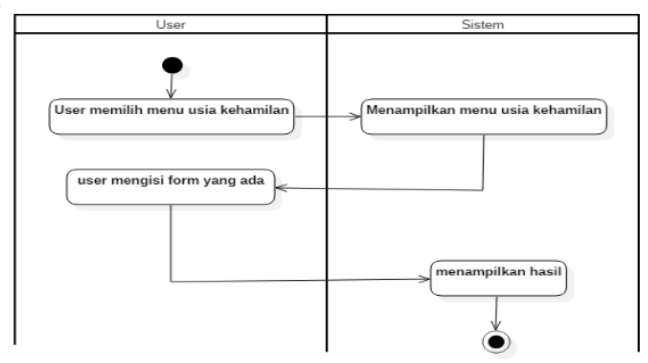

Gambar III.2 Activity Diagram Usia Kehamilan 


\section{Activity Diagram Tabel Berat Janin}

Activity Diagram berat jani merupakan aktifitas yang dilakukan oleh user atau pengguna untuk mengetahui apa saja yang ada di dalam menu berat janin. Dalam Activity Diagram ini terdapat beberapa aktifitas, yaitu:

a) Pengguna memilih usia kehamilan pada menu

b) Sistem menampilkan table berat janin

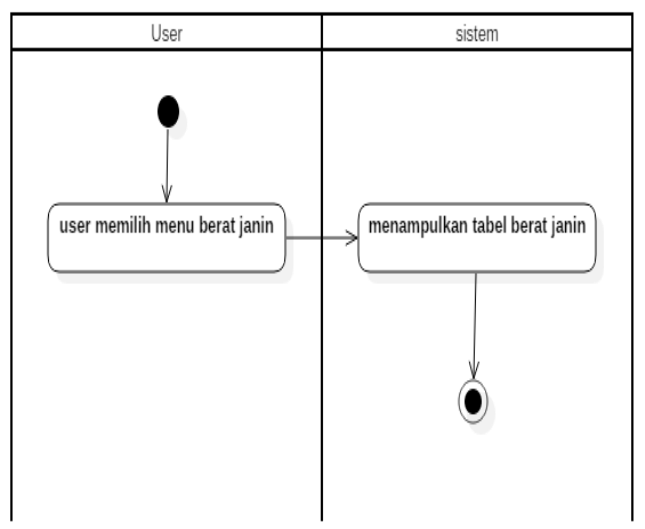

\section{Gambar III.3 Activity Diagram Tabel Berat Janin}

\section{Activity Diagram logut}

Activity Diagram Logout merupakan aktifitas yang dilakukan oleh user atau pengguna untuk keluar dari aplikasi. Dalam Activity Diagram ini terdapat beberapa aktifitas, yaitu:

a) Pengguna memilih keluar pada Menu .

b) Sistem keluar kembali menuju home.

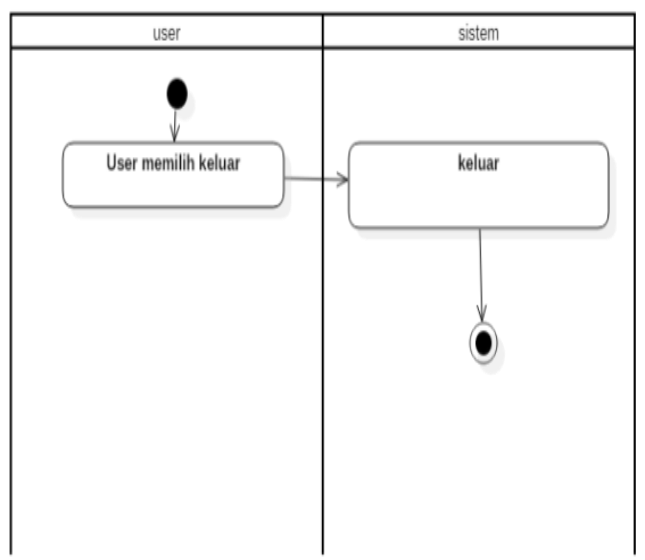

Gambar III.4 Activity Diagram logut

\section{B. Tampilan Aplikasi}

1. Tampilan Login
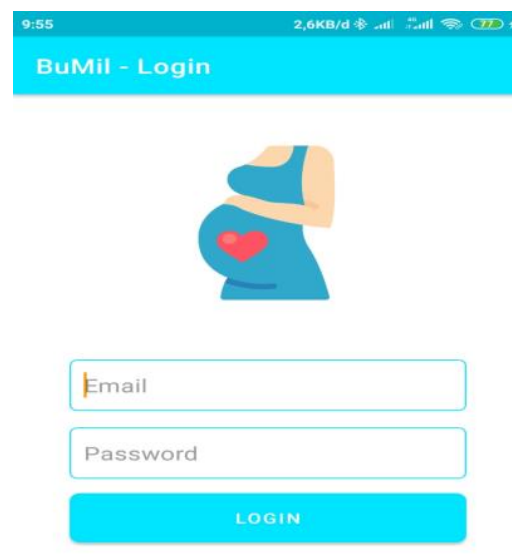

Belum Punya akun? Ayo Daftar

\section{Gambar III.5 Login}

\section{Halaman Daftar}

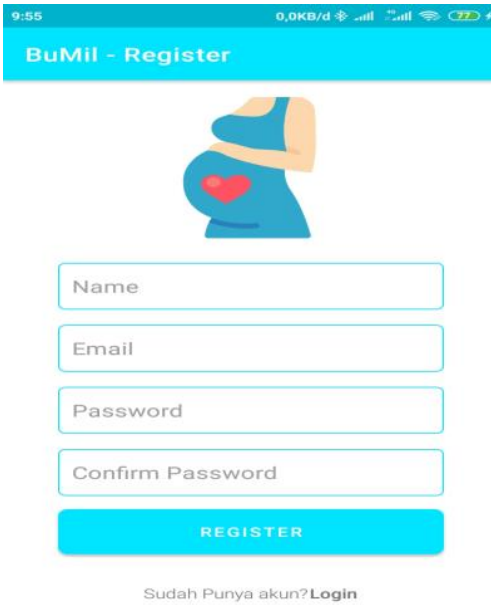

Gambar III.6 Daftar

3. Halaman Dashboard

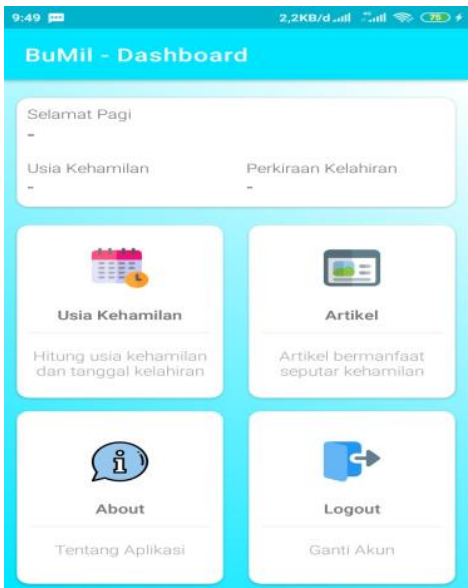

Gambar III.7 Dashboard 


\section{Halaman Usia Kehamilan}

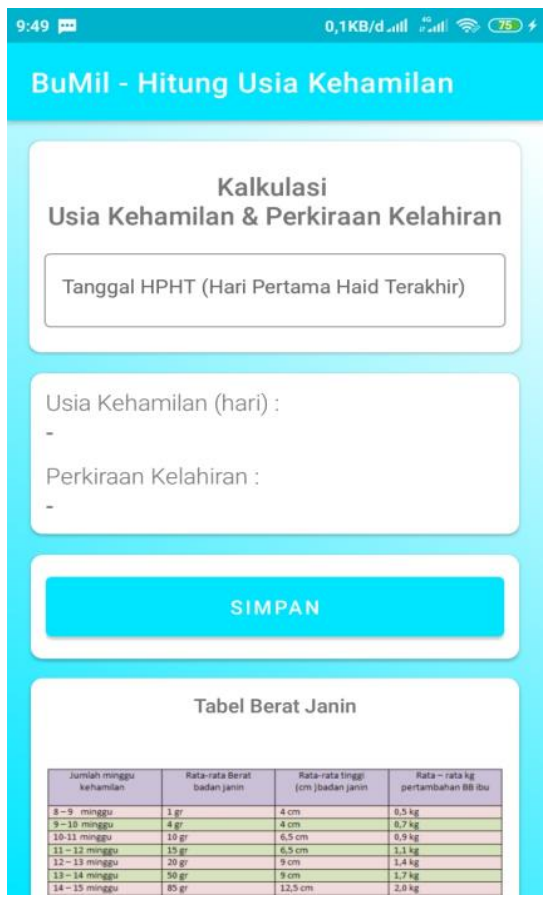

Gambar III.8 Usia Kehamilan

\section{Halaman Tabel Berat Janin}

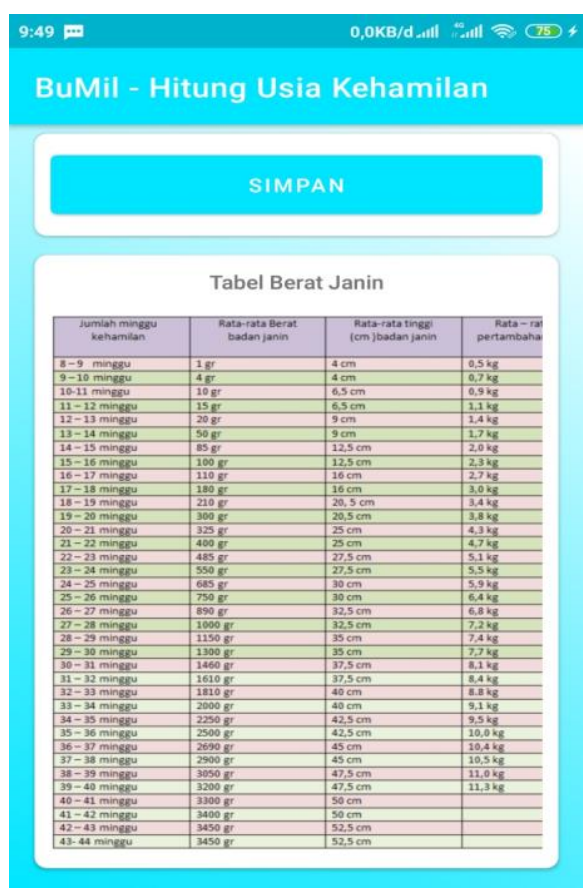

Gambar III.9 Tabel Berat Janin

\section{Kesimpulan}

Berdasarkan hasil penelitian dan pembahasan, maka didapatkan kesimpulan sebagai berikut:

Berdasarkan implementasi dan hasil pengujian aplikasi yang telah penulis buat dapat ditarik kesimpulan bahwa tujuan penelitian untuk perancangan dan pembuatan aplikasi perhitungan usia kehamilan dan berat janin menggunakan metode hari pertama haid terakhir (HPHT) berbasis android berhasil dilakukan dan diimplementasikan ke target pengguna yaitu ibu hamil yang menggunakan smartphone berbasis Android.

Hasil pengujian menunjukkan aplikasi telah benar dan tidak memiliki kesalahan baik dari segi logika maupun fungsi dan layak untuk diimplementasikan. Hasil pengujia aplikasi telah benar dan tidak memiliki kesalahan fungsi pada semua bahan uji dan layak untuk diimplementasikan.

Hasil menunjukan dengan kemajuan teknologi kini ibu hamil sanagat erat dengan smartphone berbasi android sehingga aplikasi yang penulis buat mempermudah ibu hamil atau keluarga berenca menyiapkan hari kelahiran dan mempermudah pengguna untuk menentukan gizi yang baik untuk sang ibu

\subsection{Kesimpulan}

Berdasarkan kesimpulan yang telah dijabarkan, Apabila ada yang berminat untuk mengembangkan aplikasi dalam penelitian ini, maka disarankan hal-hal sebagai berikut:

Penambahan fitur monitoring perkembangan janin dengan pendekatan jumlah tendangan bayi per satuan waktu, Penambahan fitur saran nama bayi, dan Penambahan penyedia produk ibu hamil dan bayi

\section{Referens}

Android, D. (2020). Mengenal Android Studio. Developer Android. https://developer.android.com/studio/intro ?hl=id

Anwar, S. N., Nugroho, I., \& Lestariningsih, E. (2015). Perancangan Dan Implementasi Aplikasi Mobile Semarang. Dinamika Informatika, 5(2), 135-145.

Carudin, C., \& Apriningrum, N. (2018). Aplikasi Kalender Kehamilan (Smart Pregnancy) Berbasis Android. Jurnal Online Informatika, 2(2), 116. https://doi.org/10.15575/join.v2i2.125

Dharmawan, E. A., Ginting, S. W., \& Noya, F. (2017). Rancang Bangun Aplikasi Penentu Tarif Dasar Ojek Di Kota Ambon Berbasis Android. Jurnal Simetrik, 7(2), 38-41. https://doi.org/10.31959/JS.V7I2.45

Elliana, D., \& Kurniawati, T. (2015). Perbedaan Pengetahuan Dan Persepsi Ibu Hamil Terhadap Penerapan Model Sms Gateway. 
Jurnal Kesehatan Masyarakat, 10(2), 203. https://doi.org/10.15294/kemas.v10i2.338 2

Fajar, H., \& Suharyanto. (2019). Aplikasi Pengetahuan Kehamilan Dan Perhitungan Masa Kehamilan Berbasis Android Menggunakan Metode Algoritma Naegele. Jurnal Ilmu Pengetahuan Dan Teknologi Komputer, 4(2), 231-238.

Gumuda, S. (2015). Dynamics of the process of changes in concentration of methane in the air of ventilation currents in mines. 2(2), 13-21.

Lengkong, H. N., Sinsuw, A. A. E., \& Lumenta, A. S. M. (2015). Perancangan Penunjuk Rute Pada Kendaraan Pribadi Menggunakan Aplikasi Mobile Gis Berbasis Android Yang Terintegrasi Pada Google Maps. E-Journal Teknik Elektro Dan Komputer, 4(2), 18-25. https://doi.org/10.35793/jtek.4.2.2015.681 7

Maulana, G. G. (2017). Pembelajaran Dasar algoritma dan Pemograman El-goritma berbasis WEB. Jurnal Teknik Mesin (JTM), 06, 1-5.
Oktarino A. (2015). Perancangan Sistem Nformasi Rekam Medis Pasien Pada Klinik Bersalin Kasih Ibu Menggunakan Metode Waterfall. SCIENTIA JOURNAL No.3, 4(3), 239-247. http://ojs.stikesprimajambi.ac.id/index.php/sc/article/download/ 123/119

Prasojo, S., Fadilah, U., \& Sulaiman, M. (2015). Motivasi Ibu Hamil Untuk Melakukan Pemeriksaan Kehamilan. Jurnal Ilmiah Kesehatan, 8(2), 96837.

Reza Faisal, M., \& T Nugrahadi, D. (2019). Belajar Data Science Klasifikasi dengan Bahasa Pemrograman R (Issue March).

Tawakal, H. A., Imaduddin, Z., \& Prasetyo, I. (2015). Sistem informasi dan monitoring perkembangan janin berbasis android. Jurnal Teknologi Terpadu, 1(1), 31-37.

Venny, E., Yasdinuk, H., \& Dony, N. (2014). Mobile Asisten Kehamilan Berbasis Android. Jurnal Vokasional Teknik Elektronika \& Informatika, 2(2), 106-111. https://jurnal.stikesyatsi.ac.id/index.php/k esehatan/article/view/11/4

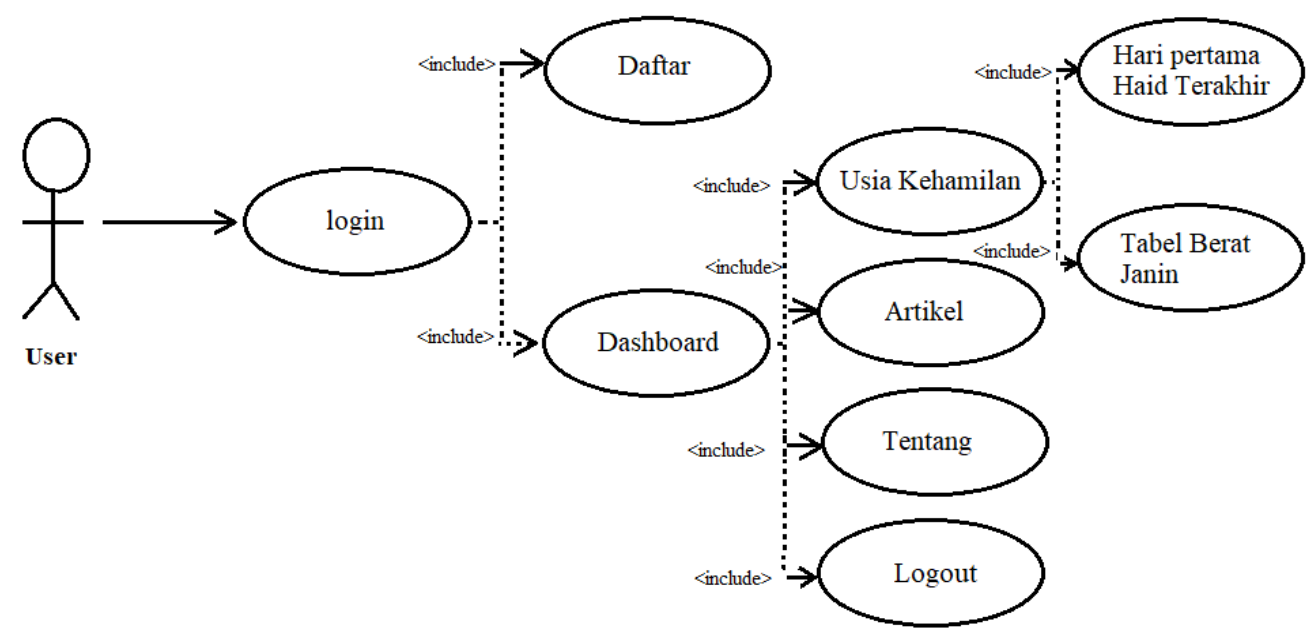

Gambar III.1 Use Case Diagram 